\title{
Long-Term Outcomes in the Management of Central Neuropathic Pain Syndromes: A Prospective Observational Cohort Study
}

\author{
Michael D. Staudt, Alexander John Clark, Allan S. Gordon, Mary E. Lynch, \\ Pat K. Morley-Forster, Howard Nathan, Catherine Smyth, Larry W. Stitt, \\ Cory Toth, Mark A. Ware, Dwight E. Moulin
}

\begin{abstract}
Background: Central neuropathic pain syndromes are a result of central nervous system injury, most commonly related to stroke, traumatic spinal cord injury, or multiple sclerosis. These syndromes are distinctly less common than peripheral neuropathic pain, and less is known regarding the underlying pathophysiology, appropriate pharmacotherapy, and long-term outcomes. The objective of this study was to determine the long-term clinical effectiveness of the management of central neuropathic pain relative to peripheral neuropathic pain at tertiary pain centers. Methods: Patients diagnosed with central $(n=79)$ and peripheral $(n=710)$ neuropathic pain were identified for analysis from a prospective observational cohort study of patients with chronic neuropathic pain recruited from seven Canadian tertiary pain centers. Data regarding patient characteristics, analgesic use, and patient-reported outcomes were collected at baseline and 12-month follow-up. The primary outcome measure was the composite of a reduction in average pain intensity and pain interference. Secondary outcome measures included assessments of function, mood, quality of life, catastrophizing, and patient satisfaction. Results: At 12-month follow-up, 13.5\% (95\% confidence interval [CI], 5.6-25.8) of patients with central neuropathic pain and complete data sets $(n=52)$ achieved a $\geq 30 \%$ reduction in pain, whereas 38.5\% (95\% CI, 25.3-53.0) achieved a reduction of at least 1 point on the Pain Interference Scale. The proportion of patients with central neuropathic pain achieving both these measures, and thus the primary outcome, was $9.6 \%$ (95\% CI, 3.2-21.0). Patients with peripheral neuropathic pain and complete data sets $(n=463)$ were more likely to achieve this primary outcome at 12 months (25.3\% of patients; $95 \%$ CI, 21.4-29.5) $(p=0.012)$. Conclusion: Patients with central neuropathic pain syndromes managed in tertiary care centers were less likely to achieve a meaningful improvement in pain and function compared with patients with peripheral neuropathic pain at 12-month follow-up.
\end{abstract}

RÉSUMÉ: Évolution à long terme de l'état de santé de patients pris en charge en raison de douleurs neuropathiques avec atteinte du système nerveux central. Contexte: Les syndromes de douleurs neuropathiques avec atteinte du système nerveux central résultent d'un dommage causé au système nerveux central. Un tel dommage est le plus couramment relié à un AVC, à une lésion traumatique de la moelle épinière ou à la sclérose en plaques (SP). Fait à souligner, de tels syndromes sont nettement moins fréquents que ceux présentant des douleurs neuropathiques du système nerveux périphérique ; ils sont aussi moins connus en ce qui a trait à leur physiopathologie sous-jacente, à un traitement pharmacologique qui leur serait approprié et à l'évolution à long terme des patients atteints. L'objectif de cette étude était donc de déterminer, dans des centres de soins tertiaires spécialisés dans la douleur, l'efficacité clinique à long terme de la prise en charge de ces douleurs neuropathiques avec atteinte du système nerveux central par rapport aux douleurs neuropathiques avec atteinte du système nerveux périphérique. Méthodes: Dans le cadre d'une étude observationnelle de cohorte prospective, on a ainsi identifié à des fins d'analyse des patients chez qui l'on avait diagnostiqué des douleurs neuropathiques chroniques avec atteinte du système nerveux central $(\mathrm{n}=79)$ ou du système nerveux périphérique $(\mathrm{n}=710)$. À noter que ces patients avaient été recrutés dans sept centres de soins tertiaires canadiens spécialisés dans la douleur. Au début de l'étude et lors d'un suivi effectué 12 mois plus tard, on a alors collecté des données concernant leurs caractéristiques, leur usage d'analgésiques et l'évolution, rapportée par eux-mêmes, de leur état de santé. Le critère d'évaluation principal de l'étude a résulté d'un amalgame établi entre la réduction de l'intensité des douleurs et le degré d'interférence lié à ces dernières. Des critères d'évaluation secondaires ont inclus une évaluation des fonctions, de l'humeur, de la qualité de vie, de la prégnance de pensées catastrophiques et de la satisfaction des patients. Résultats: Au moment du suivi effectuée 12 mois plus tard, 13,5\% (IC 95\%: 5,6-25,8) des patients souffrant de douleurs neuropathiques avec atteinte du système nerveux central et dont les données étaient complètes $(\mathrm{n}=52)$ donnaient à voir une réduction de la douleur $\geq 30 \%$. Fait à noter, 38,5\% d'entre eux (IC $95 \%: 25,3-53,0)$ ont aussi donné à voir une réduction d'au moins 1 point à l'échelle d'interférence de la

From the Department of Clinical Neurological Sciences, Western University, London, Ontario, Canada (MDS, DEM); Department of Anesthesia, Pain Management \& Perioperative

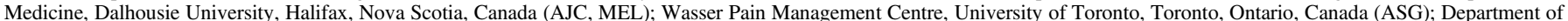

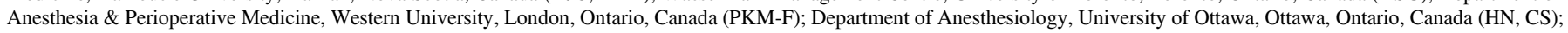

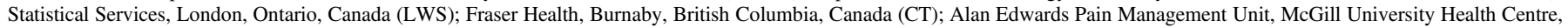
Montreal, Canada (MAW)

Received January 9, 2018. Final Revisions Submitted April 13, 2018. Date of Acceptance April 17, 2018.

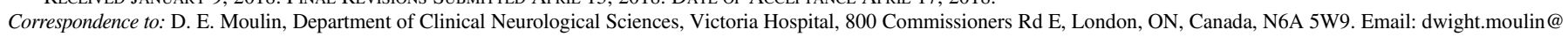
lhsc.on.ca 
douleur (Pain Interference Scale). Cela dit, la proportion de patients souffrant de douleurs neuropathiques avec atteinte du système nerveux central ayant atteint ces scores, et satisfaisant donc à notre principal critère d'évaluation, a été de 9,6\% (IC 95\%: 3,2-21.0). Enfin, les patients souffrant de douleurs neuropathiques avec atteinte au système nerveux périphérique et dont les données étaient complètes $(\mathrm{n}=463)$ étaient plus susceptibles de satisfaire au critère principal 12 mois après les débuts de l'étude (25,3\% d'entre eux; IC $95 \%: 21,4-29,5 ; p=0,012)$. Conclusions: En somme, les patients atteints d'un syndrome de douleurs neuropathiques avec atteinte du système nerveux central et pris en charge dans un centre de soins tertiaires étaient moins susceptibles, lors d'un suivi effectué 12 mois après les débuts de l'étude, de parvenir à une amélioration notable de leur état (douleurs et fonctions) si on les compare aux patients souffrant de douleurs neuropathiques avec atteinte du système nerveux périphérique.

Keywords: Central neuropathic pain, Peripheral neuropathic pain, Health-related quality of life, Central post-stroke pain, Spinal cord injury, Multiple sclerosis, Outcomes

doi:10.1017/cjn.2018.55

Can J Neurol Sci. 2018; 45: 545-552

\section{INTRODUCTION}

\section{Background}

Neuropathic pain has been defined as "pain caused by a lesion or disease of the somatosensory system.", Specifically, central neuropathic pain develops from an injury to the central nervous system (CNS) (brain, brainstem, or spinal cord), and includes diverse etiologies such as trauma, infarction, demyelination, or neoplasia. The most common central neuropathic pain syndromes are a result of stroke, referred to as central post-stroke pain (CPSP), spinal cord injury (SCI), or multiple sclerosis (MS). These pain syndromes are much less common than peripheral etiologies, and consequently less is known regarding optimal treatment and long-term outcomes.

Few randomized controlled trials have been performed to assess the efficacy of pharmacotherapy for specific central neuropathic pain syndromes, and evidence can be conflicting. ${ }^{3}$ In general, the pharmacological management of central and peripheral neuropathic pain is similar. Guidelines based on meta-analyses and expert consensus have recommended the use of gabapentinoids, serotonin-norepinephrine reuptake inhibitors and tricyclic antidepressants as first-line therapy. ${ }^{4,5}$ Despite widespread prescription, opioid analgesics are considered second or third-line therapy, and their long-term use may be associated unfavorable clinical outcomes. ${ }^{6}$ There is also increasing interest regarding the use of cannabinoids in treating neuropathic pain. ${ }^{7}$

\section{Objective}

The literature regarding the long-term treatment of central neuropathic pain syndromes is limited, and lacks external validity that could be applied to real-world outcomes. Recently, a database has been established to prospectively evaluate the clinical effectiveness of neuropathic pain management in Canadian tertiary care centers. ${ }^{6,8}$ Utilizing these data, the objective of the current study is to specifically determine the real-world management of central neuropathic pain relative to peripheral neuropathic pain.

\section{Materials ANd Methods}

\section{Study Design and Outcome Measures}

This clinical trial was designed based on guidelines established by the Initiative on Methods, Measurement, and Pain Assessment in Clinical Trials. ${ }^{9}$ Standard chronic pain outcome measures were obtained at baseline, 3, 6, and 12 months. The primary outcome measure was the composite of a reduction of $\geq 30 \%$ in average pain intensity and 1-point drop in the Pain Interference Scale of the Brief Pain Inventory (BPI; 0-10) relative to baseline at 12 months. Secondary outcome measures were impact on function (Pain Disability Index), mood (Profile of Mood States), quality of life (12-item short form health survey [SF-12]), catastrophizing (Pain Catastrophizing Scale), and patient satisfaction (Patient Global Satisfaction Scale). Patient use of prescription medications, including opioid dosages, was recorded at baseline and at 12-month follow-up.

\section{Study Setting and Participants}

The Canadian Neuropathic Pain Database has been established as a registry of patients with neuropathic pain syndromes referred to seven Academic Tertiary Pain Centers. ${ }^{6}$ From this registry, a prospective observational cohort study identified patients with central $(n=79)$ and peripheral neuropathic pain $(n=710)$. Demographic variables collected from study participants included age, sex, pain duration, level of education, smoking status, analgesic and marijuana use, comorbidities, and disability compensation. The diagnosis of neuropathic pain was based on clinical criteria and supported by validated questionnaires (Douleur Neuropathique en 4 [DN4]). ${ }^{10,11}$ Initial patient assessment and subsequent follow-ups were conducted in-person at each Pain Center. Study follow-up was arranged for 3, 6, and 12 months in all patients to assess the efficacy of treatment.

This study was approved by independent review boards representing each participating institution (University of Calgary, Alberta; Western University, McMaster University, University of Toronto and University of Ottawa, Ontario; McGill University, Quebec; Capital District Health Authority Research Ethics Board, Nova Scotia).

\section{Statistical Methods}

Between-group differences in baseline patient characteristics were made using $\chi^{2}$ tests or Fisher's exact test for categorical characteristics and unpaired $t$-tests for continuous characteristics except for pain duration, for which a Wilcoxon two-sample test was performed. Between-group comparisons regarding analgesic history were made using $\chi^{2}$ tests and, for opioid dose, Wilcoxon two-sample tests. The means and standard deviations for continuous characteristics, and frequencies and percentages for categorical characteristics, were calculated for baseline and for 12-month follow-up. 95\% confidence intervals (CIs) are included for the composite outcome. McNemar's $\chi^{2}$ test was used for dichotomous values to assess the change in the proportion of patients using major classes of analgesics (analgesic antidepressants, anticonvulsants, opioid analgesics) from 
baseline to the 12-month follow-up. The change in the opioid dose was evaluated using a signed-rank test.

Fisher's exact test was used to detect any difference in responder rate (achievement of primary outcome) between those being treated with two analgesic classes and those being treated with all three classes. For secondary outcome measures, baseline and 12 month values were compared using paired $t$-tests. The $p$-value comparing secondary outcomes was obtained by using an unpaired $t$-test comparing the changes in the two groups (central vs. peripheral), equivalent to the interaction between time (baseline vs. follow-up) and group (peripheral vs central). Betweengroup comparisons were made using an unpaired $t$-test for the difference in primary outcome based on opioid doses.

Descriptive statistics include means and standard deviations or medians and quartiles for continuous variables and frequencies and percentages for categorical variables. Between-group comparisons of the central neuropathic pain subjects with the peripheral pain subjects were made using $\chi^{2}$ tests, or Fisher's exact tests where expected cell sizes were less than five, for dichotomous variables and unpaired $t$-tests, or Wilcoxon's two-sample tests where data were not normally distributed, for continuous variables. To quantify the primary endpoint (composite of a reduction of $\geq 30 \%$ in average pain intensity and 1-point drop in the Pain Interference Scale of the BPI relative to baseline at 12 months), 95\% CIs were calculated for the percentages within the two groups and for the percentage differences between the two groups. For secondary outcomes the 12-month change from baseline was calculated, along with the associated $95 \%$ CIs, were calculated and the between-group differences compared using unpaired $t$-tests.

McNemar's $\chi^{2}$ test was used to assess the change in the proportion of subjects using major classes of analgesics from baseline to the 12-month follow-up in the central neuropathic pain group while the change in the opioid dose was evaluated using a signed-rank test.

\section{ReSUlts}

\section{Participants and Descriptive Data}

Figure 1 demonstrates patient flow through the study. A total of 789 patients fulfilled eligibility for recruitment into the

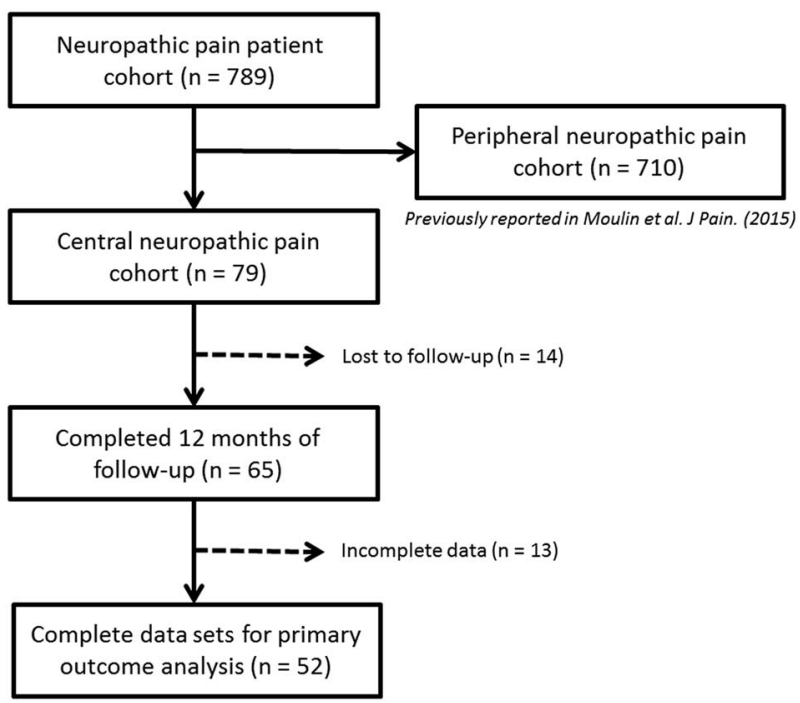

Figure 1: Flow diagram of study participants.
Canadian Neuropathic Pain Database. Of these patients, 80 were identified as having central neuropathic pain, 79 of which were included in the current analysis (Table 1). One patient was excluded, as further review identified their pain as being peripheral in origin. The baseline characteristics and analgesic history of these 79 patients are outlined in Tables 2 and 3, respectively, with comparison to patients with peripheral neuropathic pain. Additional 14 patients were lost to follow-up $(17.7 \%)$. The data from 65 patients were available for statistical evaluation, of which 52 patients had completed data sets at 12-month follow-up. The diagnostic details of the 710 patients with peripheral neuropathic pain were previously published. ${ }^{6}$ Complete data sets were available for 463 of these patients.

\section{Outcome Data: Main Results}

The proportion of patients achieving a $\geq 30 \%$ reduction in pain at 12 months relative to baseline was $7 / 52$ or $13.5 \%$ (95\% CI, 5.625.8), whereas those achieving a reduction of at least 1 point on the Pain Interference Scale was 20/52 or $38.5 \%$ (95\% CI, 25.353.0) (Table 4). The proportion of patients reaching the primary outcome, including both $a \geq 30 \%$ reduction in pain and 1 point reduction on the Pain Interference Scale, was $5 / 52$ or $9.6 \%(95 \%$ CI, 3.2-21.0). In comparison, patients with peripheral neuropathic pain syndromes were more likely to achieve this primary outcome at 12 months $(25.3 \%$ of patients; 95\% CI, 21.4-29.5) (difference [95\% CI] of $15.7 \%$ [6.7\%-24.6\%], $p=0.012$ ).

\section{Outcome Data: Secondary Analyses}

For secondary outcome measures, only mean pain intensity and mean Interference Scale Score were significantly improved at 12-month follow-up relative to baseline $(p=0.031$ and $p=0.044$, respectively). The additional outcome measures, including Profile

Table 1: Location and etiology of central neuropathic pain syndromes $(n=79)$

\begin{tabular}{l|c}
\hline Cranial $(n=17)$ & \\
\hline Stroke & $11(13.9 \%)$ \\
\hline Trauma & $1(1.3 \%)$ \\
\hline Multiple sclerosis & $1(1.3 \%)$ \\
\hline Tumor & $1(1.3 \%)$ \\
\hline Neurodegenerative & $1(1.3 \%)$ \\
\hline Idiopathic & $2(2.5 \%)$ \\
\hline Spinal $(n=62)$ & \\
\hline Stroke & $1(1.3 \%)$ \\
\hline Trauma & $13(16.5 \%)$ \\
\hline Multiple sclerosis & $21(26.6 \%)$ \\
\hline Tumor & $4(5.1 \%)$ \\
\hline Inflammatory & $1(1.3 \%)$ \\
\hline Syrinx & $5(6.3 \%)$ \\
\hline Deformity (congenital or acquired) & $6(7.6 \%)$ \\
\hline Post-surgical & $7(8.9 \%)$ \\
\hline Post-radiation & $1(1.3 \%)$ \\
\hline Idiopathic & $3(3.8 \%)$ \\
\hline
\end{tabular}




\section{Table 2: Patient characteristics at baseline}

\begin{tabular}{|c|c|c|c|}
\hline & $\begin{array}{l}\text { Central } \\
(n=79)\end{array}$ & $\begin{array}{l}\text { Peripheral } \\
(n=710)\end{array}$ & $p$ Value \\
\hline Age (years, $n[\%]$ ) & $52.9 \pm 11.3$ & $53.6 \pm 14.5$ & 0.698 \\
\hline $\operatorname{Sex}(M)$ & $46(58.2 \%)$ & $311(43.8 \%)$ & 0.015 \\
\hline DN4 score $(0-10)$ & $6.5 \pm 2.1$ & $5.7 \pm 2.3$ & 0.003 \\
\hline $\mathrm{DN} 4 \geq 4(n[\%])$ & $73(92.4 \%)$ & $579(81.6 \%)$ & 0.016 \\
\hline Pain duration (years) & & & 0.002 \\
\hline Mean & $6.5 \pm 6.8$ & $4.7 \pm 5.7$ & \\
\hline Median & $4.0(2,10)$ & $3.0(1,6)$ & \\
\hline Average pain intensity $(0-10, \mathrm{BPI})$ & $6.3 \pm 1.8$ & $6.0(1.9)$ & 0.290 \\
\hline $\begin{array}{l}\text { Average Interference Scale Score } \\
\quad(0-10, \mathrm{BPI})\end{array}$ & $6.2 \pm 2.5$ & $6.0 \pm 2.4$ & 0.487 \\
\hline Education $(n[\%])$ & & & 0.038 \\
\hline Primary school & $1(1.3 \%)$ & $41(5.8 \%)$ & \\
\hline Secondary school & $22(27.9 \%)$ & $261(37.1 \%)$ & \\
\hline College or university & $55(69.6 \%)$ & $399(56.7 \%)$ & \\
\hline Smoking status $(n[\%])$ & & & 0.233 \\
\hline Current & $28(35.4 \%)$ & $187(26.5 \%)$ & \\
\hline Previous & $22(27.9 \%)$ & $218(30.8 \%)$ & \\
\hline Marijuana use (current) ( $n[\%]$ ) & $16(20.5 \%)$ & $71(10.2 \%)$ & 0.006 \\
\hline \multicolumn{4}{|l|}{ Comorbidities $(n[\%])$} \\
\hline Mechanical neck or back pain & $10(12.7 \%)$ & $105(15.0 \%)$ & 0.585 \\
\hline Fibromyalgia & $1(1.3 \%)$ & $21(3.0 \%)$ & 0.716 \\
\hline Headache & $4(5.1 \%)$ & $14(2.0 \%)$ & 0.096 \\
\hline Disability compensation ( $n[\%])$ & $33(41.8 \%)$ & $186(26.3 \%)$ & 0.004 \\
\hline
\end{tabular}

DN4 = Douleur Neuropathique en 4 Questions: score $\geq 4$ indicates

probable neuropathic pain; $\mathrm{M}=$ male.

Data are mean \pm standard deviation, median $(\mathrm{Q} 1, \mathrm{Q} 3)$.

of Moods State, SF-12 Mental, SF-12 Physical, Pain Disability Index, Pain Catastrophizing Scale and Patient Global Satisfaction did not achieve significance (Table 5). In comparison, patients with peripheral neuropathic pain achieved significant improvement in all secondary outcomes at 12 -month follow-up relative to baseline $(p<0.001)$. When comparing the two groups, patients with peripheral neuropathic pain were more likely to report improvements in Profile of Moods State, Pain Disability Index, and Pain Catastrophizing Scale $(p=0.006, p=0.034$, and $p=0.030$, respectively).

The proportion of patients with central neuropathic pain using analgesic antidepressants, anticonvulsants, or opioids was unchanged at 12-month follow-up relative to baseline (Table 6). However, combination therapy was common with about $30 \%$ of patients receiving two of the three major classes of analgesics for neuropathic pain (antidepressants, anticonvulsants, and opioid analgesics) and about $17 \%$ treated with all three classes of analgesics concurrently at 12-month follow-up. ${ }^{6}$ Opioids were routinely used by $37 / 65(56.9 \%)$ of patients at 12 -month followup, which represented a non-statistically significant decrease from $43 / 65(66.2 \%)$ of patients at baseline. In total, 31 patients used opioids at both baseline and in follow-up, without any significant change in dosage (Table 7).
Table 3: Patient analgesic history

\begin{tabular}{|c|c|c|c|}
\hline & $\begin{array}{l}\text { Central } \\
(n=79)\end{array}$ & $\begin{array}{c}\text { Peripheral } \\
(n=710)\end{array}$ & $p$ Value \\
\hline \multicolumn{4}{|l|}{ Baseline analgesics $(n[\%])$} \\
\hline None & $2(2.5 \%)$ & $70(9.9 \%)$ & 0.032 \\
\hline NSAIDs & $42(53.2 \%)$ & $394(55.5 \%)$ & 0.693 \\
\hline Analgesic antidepressants & $28(35.4 \%)$ & $177(24.9 \%)$ & 0.043 \\
\hline Anticonvulsants & $51(64.6 \%)$ & $317(44.7 \%)$ & $<0.001$ \\
\hline Opioids & $51(64.6 \%)$ & $357(50.3 \%)$ & 0.016 \\
\hline Opioid dose (MED) & & & 0.291 \\
\hline Mean & $104.8 \pm 146.4$ & $102.9 \pm 172.9$ & \\
\hline Median & $60.0(20,150)$ & $40.0(18,120)$ & \\
\hline \multicolumn{4}{|l|}{ Prior analgesic trials $(n[\%])$} \\
\hline None & $24(30.4 \%)$ & $200(28.2 \%)$ & 0.679 \\
\hline NSAIDS & $30(38.0 \%)$ & $344(48.5 \%)$ & 0.077 \\
\hline Analgesic antidepressants & $20(25.3 \%)$ & $110(15.5 \%)$ & 0.026 \\
\hline Anticonvulsants & $20(25.3 \%)$ & $180(25.4 \%)$ & 0.995 \\
\hline Opioids & $19(24.1 \%)$ & $211(29.7 \%)$ & 0.293 \\
\hline Opioid dose (MED) & & & 0.068 \\
\hline Mean & $36.2 \pm 51.6$ & $68.4 \pm 125.2$ & \\
\hline Median & $20.0(5,30)$ & $33.8(10,68)$ & \\
\hline
\end{tabular}

$\mathrm{MED}=$ morphine equivalent dose (mg/day); NSAIDS $=$ nonsteroidal

anti-inflammatory drugs.

Data are mean \pm standard deviation, median $(\mathrm{Q} 1, \mathrm{Q} 3)$.

A number of non-pharmacological treatment modalities were commonly employed by patients with central neuropathic pain. The most commonly used by 12 months were physiotherapy and acupuncture, reported by $56.9 \%$ and $40.0 \%$ of patients, respectively. Local anesthetic or steroid injections were utilized by $24.6 \%$ of patients. Other methods included transcutaneous electrical nerve stimulation (20.0\%), psychotherapy (15.4\%), surgery (13.9\%), and local anesthetic infusions (10.8\%).

\section{Discussion}

The primary outcome measure for this study was the proportion of patients achieving both at least a $30 \%$ reduction in average pain intensity and a 1-point reduction in the Interference Scale Score of the BPI at 12 months. ${ }^{12}$ These were chosen as they represent a clinically significant improvement in both pain and function. Only $9.6 \%$ of patients with central neuropathic pain achieved this outcome compared with $25.3 \%$ of patients with peripheral neuropathic pain. Interestingly, more patients with central neuropathic pain achieved a functional improvement $(38.5 \%)$ compared with pain reduction (13.5\%). The overall low success rate may be attributed to several factors, including the lack of specific therapeutic agents available to treat central neuropathic pain syndromes. The median pain duration was 4.0 years, suggesting that pain control had been refractory to conventional treatments initiated in a primary care setting; in addition, between $24.1 \%$ and $38 \%$ of patients had previously tried different analgesic classes and combination therapy was common among the entire cohort during the study. Furthermore, 
Table 4: Primary endpoint and its components at month 12

\begin{tabular}{|c|c|c|c|c|c|c|}
\hline & \multicolumn{2}{|c|}{ Central pain } & \multicolumn{2}{|c|}{ Peripheral pain } & \multicolumn{2}{|l|}{ Difference } \\
\hline & $\mathbf{f} / n(\%)$ & $95 \% \mathrm{CI}$ & $\mathbf{f} / n(\%)$ & $95 \% \mathrm{CI}$ & Difference (95\% CI) & $p$ Value \\
\hline$\geq 30 \%$ reduction in pain & $7 / 52(13.5 \%)$ & $5.6 \%-25.8 \%$ & $160 / 463(34.6 \%)$ & $30.2 \%-39.1 \%$ & $21.1 \%(10.9 \%-31.3 \%)$ & 0.002 \\
\hline$\geq 1$-point reduction on Pain Interference Scale & $20 / 52(38.5 \%)$ & $25.3 \%-53.0 \%$ & $220 / 465(47.3 \%)$ & $42.7 \%-52.0 \%$ & $8.9 \%(-5.1 \%$ to $22.8 \%)$ & 0.225 \\
\hline $\begin{array}{l}\text { Both } \geq 30 \% \text { reduction in pain and } \geq 1 \text {-point reduction on Pain } \\
\text { Interference Scale }\end{array}$ & $5 / 52(9.6 \%)$ & $3.2 \%-21.0 \%$ & $117 / 463(25.3 \%)$ & $21.4 \%-29.5 \%$ & $15.7 \%(6.7 \%-24.6 \%)$ & 0.012 \\
\hline
\end{tabular}

$\mathrm{CI}=$ confidence interval .

conducting this study at tertiary care centers is more likely to introduce a referral bias, with more complex patients being included in the analysis.

Diagnosing and distinguishing central neuropathic pain from other pain etiologies is essential to facilitate optimal care. Patients with neuropathic pain often suffer from comorbid musculoskeletal nociceptive pain and spasticity secondary to limb disuse and impaired mobility. ${ }^{3}$ Allodynia and hyperalgesia, which reflect aberrant pain signaling, can be general features of both central and peripheral etiologies. Other pain characteristics allow further discrimination, including the temporal relation to a CNS injury, and distribution of pain within the area affected by the injury. ${ }^{3}$ Validated outcome measures, such as the DN4 Questions, allows for screening of central neuropathic pain syndromes with high sensitivity. ${ }^{11}$

The etiologies resulting in central neuropathic pain syndromes are heterogeneous, and most commonly include CPSP, SCI, and MS. ${ }^{13}$ Accordingly, these three etiologies represented $47 / 79$ or $59.5 \%$ of patients included in the current analysis. However, any lesion of the CNS can be implicated in the development of central neuropathic pain, including demyelination, tumors, trauma, syringomyelia, and sequela of surgery or radiation. Central neuropathic pain syndromes are distinctly less common than peripheral neuropathic pain, and as such our understanding is limited regarding the natural history of these disorders, optimal treatment paradigms, and long-term outcomes. ${ }^{3}$ To our knowledge, the observations of the current study are the first to prospectively evaluate 12-month real-world treatment outcomes of a variety of central neuropathic pain etiologies. Patients with central neuropathic pain rarely achieve significant long-term benefit and are significantly less likely to respond to treatment than patients with peripheral neuropathic pain.

Neuropathic pain is associated with a lower health-related quality of life and suboptimal patient-reported outcomes. ${ }^{14} \mathrm{~A}$ previous cross-sectional study of community-based practices in the United States reported associations between severe neuropathic pain and poor function, less sleep, and increased anxiety and depression. ${ }^{15}$ Although both peripheral and central neuropathic pain reported similar disability, only central neuropathic pain related to SCI was included in this analysis. The natural history of central neuropathic pain is not known, although studies of patients with chronic pain related to $\mathrm{SCI}^{16,17}$ and $\mathrm{MS}^{18}$

Table 5: Changes from month 0 to month 12 for secondary outcome measures

\begin{tabular}{|c|c|c|c|c|c|c|c|c|c|c|c|}
\hline & \multicolumn{5}{|c|}{ Central } & \multicolumn{4}{|c|}{ Peripheral } & \multirow{3}{*}{$\begin{array}{c}\text { Difference } \\
\begin{array}{c}\text { Difference } \\
(95 \% \mathrm{CI})\end{array}\end{array}$} & \multirow{3}{*}{$\begin{array}{c}\begin{array}{c}\text { Central vs. } \\
\text { peripheral }\end{array} \\
p \text { Value }\end{array}$} \\
\hline & \multicolumn{2}{|c|}{ Month 0} & \multicolumn{2}{|c|}{ Month 12} & \multirow{2}{*}{$\begin{array}{c}\text { Difference } \\
\text { Difference } \\
(95 \% \mathrm{CI})\end{array}$} & \multicolumn{2}{|c|}{ Month 0} & \multicolumn{2}{|c|}{ Month 12} & & \\
\hline & $n$ & $\begin{array}{c}\text { Mean } \\
\text { (SD) }\end{array}$ & $n$ & $\begin{array}{l}\text { Mean } \\
\text { (SD) }\end{array}$ & & $n$ & $\begin{array}{c}\text { Mean } \\
\text { (SD) }\end{array}$ & $n$ & $\begin{array}{c}\text { Mean } \\
\text { (SD) }\end{array}$ & & \\
\hline $\begin{array}{l}\text { Average pain intensity, } \\
\text { BPI }\end{array}$ & 77 & $6.29(1.83)$ & 54 & $5.61(1.87)$ & $0.60(0.06,1.14)$ & 686 & $6.04(1.95)$ & 483 & $4.90(2.39)$ & $1.16(0.96,1.37)$ & 0.079 \\
\hline $\begin{array}{l}\text { Mean Interference } \\
\text { Scale score, BPI }\end{array}$ & 77 & $6.17(2.47)$ & 54 & $5.21(2.74)$ & $0.71(0.02,1.40)$ & 687 & $5.96(2.45)$ & 484 & $4.73(2.88)$ & $1.17(0.95,1.38)$ & 0.181 \\
\hline POMS-Short Form & 77 & $47.9(20.8)$ & 52 & $46.1(21.4)$ & $-1.8(-7.3,3.6)$ & 687 & $50.1(22.7)$ & 473 & $43.7(21.2)$ & $5.5(3.9,7.2)$ & 0.006 \\
\hline SF-12 Mental & 74 & $44.3(10.5)$ & 52 & $46.0(10.9)$ & $-0.4(-3.1,2.3)$ & 683 & $41.0(12.0)$ & 483 & $43.0(11.9)$ & $-1.7(-2.7,-0.7)$ & 0.412 \\
\hline SF-12 Physical & 74 & $29.4(8.5)$ & 52 & $29.4(9.6)$ & $-0.5(-2.9,1.8)$ & 683 & $33.1(9.8)$ & 483 & $34.9(10.7)$ & $-1.9(-2.7,-1.1)$ & 0.285 \\
\hline $\begin{array}{l}\text { Pain Disability Index } \\
\quad \text { (PDI) }\end{array}$ & 78 & $38.2(16.3)$ & 53 & $36.8(17.6)$ & $1.4(-2.4,5.3)$ & 701 & $37.8(16.5)$ & 480 & $31.3(18.7)$ & $6.3(4.9,7.7)$ & 0.034 \\
\hline $\begin{array}{l}\text { Pain Catastrophizing } \\
\text { Scale }\end{array}$ & 77 & $22.2(12.1)$ & 55 & $19.5(13.2)$ & $1.9(-1.5,5.2)$ & 699 & $24.7(12.7)$ & 479 & $18.7(13.3)$ & $5.3(4.3,6.2)$ & 0.030 \\
\hline $\begin{array}{r}\text { Patient Global } \\
\text { Satisfaction }\end{array}$ & 74 & $6.50(3.15)$ & 53 & $6.55(3.09)$ & $0.18(-0.88,1.23)$ & 669 & $6.00(3.27)$ & 475 & $6.87(2.88)$ & $-0.78(-1.11,-0.44)$ & 0.082 \\
\hline
\end{tabular}

PMOS-SF = Profile of Mood States-Short Form; SF-12 = 12-item short form health survey.

BPI (0-10); PDI (0-70), higher score indicates greater disability; POMS-SF (0-120), higher score indicates greater impairment; SF-12 (0-100), score <50 indicates below average health status; Pain Catastrophizing Scale (0-52), higher score indicates greater distress; Pain Global Satisfaction (0-10), higher score indicates greater satisfaction. 
Table 6: Major analgesic class use at baseline and 12-month follow-up $(n=65)$

\begin{tabular}{l|c|c|c}
\hline Major analgesic class & $\begin{array}{c}\text { Baseline } \\
(\boldsymbol{n}[\%])\end{array}$ & $\begin{array}{c}\text { 12 months } \\
(\boldsymbol{n}[\boldsymbol{\%}])\end{array}$ & $\begin{array}{c}\boldsymbol{p} \text { Value } \\
\left(\mathbf{M c N e m a r} \boldsymbol{\chi}^{2}\right)\end{array}$ \\
\hline $\begin{array}{l}\text { Analgesic } \\
\text { antidepressants }\end{array}$ & $24(36.9 \%)$ & $26(40.0 \%)$ & 0.791 \\
\hline Anticonvulsants & $44(67.7 \%)$ & $43(66.2 \%)$ & $>0.999$ \\
\hline Opioids & $43(66.2 \%)$ & $37(56.9 \%)$ & 0.238 \\
\hline
\end{tabular}

Analgesic antidepressants refer to tricyclic antidepressants and serotonergic noradrenergic reuptake inhibitors; anticonvulsants refer primarily to gabapentin and pregabalin.

demonstrate that pain tends to worsen over time and patients become more disabled. These poor outcomes highlight the need for effective treatment paradigms; however, there is a distinct lack of prospective controlled clinical trials for central neuropathic pain. Furthermore, previous studies have often reported conflicting evidence, with specific pharmacological agents useful in one central neuropathic pain syndrome but not another. For example, pregabalin has been demonstrated to provide significant pain relief in patients with neuropathic pain secondary to SCI, ${ }^{19,20}$ but not CPSP. ${ }^{21}$ Gabapentin, a cornerstone in most neuropathic pain treatment paradigms, has mixed evidence regarding its effectiveness in SCI. ${ }^{22,23}$ Amitriptyline can be effective for CPSP, ${ }^{24}$ and for SCI patients with comorbid depression. ${ }^{23}$ Lamotrigine has generally been shown to be effective in treating both CPSP and SCI. $^{25,26}$ Both duloxetine ${ }^{27}$ and cannabinoids ${ }^{28}$ may be effective for MS-related pain.

Such disparities also exist in the treatment of other peripheral neuropathic pain syndromes, ${ }^{5}$ highlighting the need for an individualized approach to pharmacotherapy with different monotherapies or combination therapies. ${ }^{29,30}$ Given the limited data available and relative rarity of central neuropathic pain syndromes, the treatment approach to central neuropathic pain is often based on algorithms established for peripheral neuropathic pain. ${ }^{3}$ Previous meta-analyses have reported that there is no general evidence for the use of a specific drug to treat a specific pain disorder, and thus pharmacotherapy guidelines are applicable to generalized neuropathic pain. ${ }^{4,31}$ In general, first-line therapy consists of gabapentinoids, serotonin-norepinephrine reuptake inhibitors, and tricyclic antidepressants. ${ }^{5}$ Cannabinoids have recently been reported to have analgesic benefit in neuropathic pain, ${ }^{7,32}$ although their use should not be considered first-line and larger studies are required to determine appropriate indications, dosing, and efficacy.

The role of opioid analgesics in the treatment of neuropathic pain is controversial. Although previously considered first-line treatment in many paradigms, ${ }^{33}$ the current use of opioids is recommended as second or third-line therapy. ${ }^{4,6}$ This change has

Table 7: Opioid dose (morphine equivalent dose $\mathrm{mg} / \mathrm{day}$ ) in patients with opioid use at baseline and 12-month followup $(n=31)$

\begin{tabular}{l|c|c|c}
\hline & Baseline & 12 months & $\boldsymbol{p}$ Value \\
\hline Mean (standard deviation) & $125.3(176.7)$ & $129.1(136.0)$ & 0.539 \\
\hline Median & 67.5 & 80.0 & \\
\hline
\end{tabular}

been prompted by concerns regarding the potential risks of abuse and opioid-related morbidity and mortality. ${ }^{34-36}$ The efficacy of strong opioids has been described (oxycodone, morphine), primarily in peripheral neuropathic pain, with maximum effectiveness achieved at $180 \mathrm{mg}$ of morphine or morphine equivalent per day. ${ }^{4}$ In the current study, there was a small but non-significant decrease in the number of patients using opioids at baseline and 12-month follow-up, which may have reflected optimization of other adjunct therapies. A total of 31 patients with central neuropathic pain used opioids throughout the study, without any significant change in opioid dose. Results reported from the Canadian Neuropathic Pain Database demonstrate that patients with peripheral neuropathic pain and favorable outcomes at 12-month follow-up were less likely to be on opioids, or used significantly lower doses. ${ }^{6}$ However, this was not the case for patients with central neuropathic pain whose outcomes were less favorable than patients with peripheral pain.

It is not clear why central neuropathic pain was managed less effectively than peripheral neuropathic pain. Patients with peripheral pain were more likely to achieve significant pain reduction, and also reported improved secondary outcome measures including pain disability and catastrophizing. These differences cannot be explained by differences in baseline patient characteristics. Although patients with central neuropathic pain reported were more frequently male, had longer pain duration, higher usage of antidepressants, anticonvulsants, opioids (although not higher opioid doses), and marijuana use than patients with peripheral pain, pain intensity, and disability were similar at baseline. The difference is likely more complicated and related to the underlying pathophysiology of central neuropathic pain, which is poorly understood.

A primary tenet of peripheral neuropathic pain is the activation of nociceptive pathways, with resultant aberrant signaling to various pain centers in the absence of ongoing noxious stimuli. Tissue injury or inflammation alters the local chemical environment of nociceptors, which upregulates inflammatory markers and induces downstream changes that potentiate receptor signaling. ${ }^{37}$ Central sensitization then refers to intrinsic changes in pain transmission pathways, particularly in the dorsal horn of the spinal cord, which potentiates pain signals. ${ }^{38}$ In contrast, central neuropathic pain is a direct result of a CNS injury, and thus does not involve the same central sensitization mechanisms, which are sequelae of chronic pain. ${ }^{3}$ Aberrant signaling within the spinalthalamic-cortical pathways has commonly been implicated in the development of central neuropathic pain, although not all patients with spinothalamic tract lesions develop central neuropathic pain. ${ }^{39}$ It has been suggested that additional cofactors may be involved; regarding SCI for example, neuronal hyperexcitability within preserved spinothalamic tract neurons may be stimulated either directly via microglial activation or indirectly through disinhibition. ${ }^{40}$ Abnormal, spontaneous burst activity within the thalamus has been implicated in a number of central neuropathic pain syndromes, suggesting a common central origin or amplifier. ${ }^{3}$ As such, the relative poor effectiveness of pharmacotherapy in treating central neuropathic pain may thus be attributed to a number of factors, such as our limited understanding of which neurotransmitter(s) or signaling pathways should be targeted. In addition, central neuropathic pain may be intrinsically less responsive to treatment as it represents a true CNS injury, whereas peripheral pain syndromes are "stimulus evoked" and require 
potentiation with sensitization mechanisms, ${ }^{41}$ which tend to be clinically recognized earlier and thus can be inhibited or altered with medications.

Given the low success rate of treating central neuropathic syndromes, there has been renewed interest in the role of neuromodulation surgery. Unlike ablative procedures, neuromodulation is both titratable and reversible. Spinal cord stimulation is perhaps the most well-known and is commonly utilized for the treatment of failed back surgery syndrome and complex regional pain syndrome, ${ }^{42}$ and its use in CPSP has been described with varying efficacy. ${ }^{43,44}$ The use of deep brain stimulation has a longstanding history in the treatment of pain, with some of the earliest indications being CPSP, facial anesthesia dolorosa, and phantom limb pain, ${ }^{45,46}$ although pain invariably recurs and becomes refractory to stimulation. ${ }^{47}$ Motor cortex stimulation has some reported efficacy in the treatment of CPSP and trigeminal neuropathic pain, ${ }^{48,49}$ although long-term pain relief is inconsistent and tends to require intensive reprogramming. ${ }^{50,51}$ Intrathecal drug delivery has an established history in the treatment of cancerrelated pain and spasticity, with more recent interest in the use of intrathecal opioids and local anesthetics for the treatment of neuropathic pain syndromes. ${ }^{52}$ These procedures generally remain underutilized in the treatment of central neuropathic pain syndromes, although may potentially be considered as alternative therapies for refractory or intractable pain.

There are several limitations to this observational study. The primary issue is the small number of patients recruited with central neuropathic pain and the $17.7 \%$ loss to follow-up. However, this reflects the relative rarity of central neuropathic pain syndromes in the general population, and the low number of patients referred to tertiary care centers. Second, the relative heterogeneity of central neuropathic pain etiologies included in this analysis does not allow for the evaluation of specific interventions or conditions. Finally, as this was an observational study, there was no control group comprised of untreated patients. Despite these limitations, this study highlights the challenges in treating central neuropathic pain syndromes, and is the first to provide real-world evidence that central neuropathic pain is not managed as well as peripheral pain.

\section{ACKNOWLEDGMENTS}

This study was funded by Canadian Foundation for Innovation (Grant \#7878), The Earl Russell Chair in Pain Research, Western University, London, Ontario, and by Pfizer Canada.

\section{Statement of Authorship}

MDS was the primary investigator and was responsible for designing the article, interpreting and analyzing the data, and writing the manuscript. AJC, ASG, MEL, PKM-F, HN, CS, CT, MAW, and DEM assisted with the study design and revising of the article. LWS performed the statistical analysis and revised the manuscript for important intellectual content. All of the authors approved the final version of the manuscript submitted for publication and have agreed to act as guarantors of the work.

\section{Disclosures}

MDS, ASG, PKM-F, HN, LWS, and CT have nothing to disclose. AJC reports personal fees from Wex Pharmaceuticals, outside the submitted work. MEL reports other from Cannimed, other from CCIC, other from Panag Pharm Inc., outside the submitted work. In addition, MEL has a patent Cannabinoid based formulations for ocular pain issued. CS reports grants from Pfizer Canada, from null, during the conduct of the study; personal fees from Indivior, outside the submitted work. MAW reports personal fees from CHI, grants from CanniMed, outside the submitted work. DEM reports grants from Pfizer Canada, from null, during the conduct of the study.

\section{REFERENCES}

1. Jensen TS, Baron R, Haanpaa M, et al. A new definition of neuropathic pain. Pain. 2011;152(10):2204-5.

2. Treede RD, Jensen TS, Campbell JN, et al. Neuropathic pain: redefinition and a grading system for clinical and research purposes. Neurology. 2008;70(18):1630-5.

3. Watson JC, Sandroni P. Central neuropathic pain syndromes. Mayo Clinic Proc. 2016;91(3):372-85.

4. Finnerup NB, Attal N, Haroutounian S, et al. Pharmacotherapy for neuropathic pain in adults: a systematic review and meta-analysis. Lancet Neurol. 2015;14(2):162-73.

5. Moulin D, Boulanger A, Clark AJ, et al. Pharmacological management of chronic neuropathic pain: revised consensus statement from the Canadian Pain Society. Pain Res Manag. 2014;19(6): 328-335.

6. Moulin DE, Clark AJ, Gordon A, et al. Long-term outcome of the management of chronic neuropathic pain: a prospective observational study. J Pain. 2015;16(9):852-61.

7. Meng H, Johnston B, Englesakis M, Moulin DE, Bhatia A. Selective cannabinoids for chronic neuropathic pain: a systematic review and meta-analysis. Anesthesia Analgesia. 2017;125(5): 1638-52.

8. Mai LM, Clark AJ, Gordon AS, et al. Long-term outcomes in the management of painful diabetic neuropathy. Can J Neurol Sci. 2017;44(4):337-42.

9. Dworkin RH, Turk DC, Farrar JT, et al. Core outcome measures for chronic pain clinical trials: IMMPACT recommendations. Pain. 2005;113(1-2):9-19.

10. Bouhassira D, Attal N, Alchaar $\mathrm{H}$, et al. Comparison of pain syndromes associated with nervous or somatic lesions and development of a new neuropathic pain diagnostic questionnaire (DN4). Pain. 2005;114(1-2):29-36.

11. VanDenKerkhof EG, Stitt L, Clark AJ, et al. Sensitivity of the DN4 in screening for neuropathic pain syndromes. Clin J Pain. 2018; 34(1):30-6.

12. Dworkin RH, Turk DC, McDermott MP, et al. Interpreting the clinical importance of group differences in chronic pain clinical trials: IMMPACT recommendations. Pain. 2009;146(3):238-44.

13. Widerstrom-Noga E, Loeser JD, Jensen TS, Finnerup NB. AAPT diagnostic criteria for central neuropathic pain. J Pain. 2017; 18(12):1417-26.

14. Doth AH, Hansson PT, Jensen MP, Taylor RS. The burden of neuropathic pain: a systematic review and meta-analysis of health utilities. Pain. 2010;149(2):338-44.

15. Schaefer C, Mann R, Sadosky A, et al. Burden of illness associated with peripheral and central neuropathic pain among adults seeking treatment in the United States: a patient-centered evaluation. Pain Med. 2014;15(12):2105-19.

16. Stormer S, Gerner HJ, Gruninger W, et al. Chronic pain/dysaesthesiae in spinal cord injury patients: results of a multicentre study. Spinal Cord. 1997;35(7):446-55.

17. Finnerup NB, Norrbrink C, Trok K, et al. Phenotypes and predictors of pain following traumatic spinal cord injury: a prospective study. J Pain J Am Pain Soc. 2014;15(1):40-8.

18. Young J, Amatya B, Galea MP, Khan F. Chronic pain in multiple sclerosis: a 10-year longitudinal study. Scand J Pain. 2017; 16:198-203.

19. Siddall PJ, Cousins MJ, Otte A, Griesing T, Chambers R, Murphy TK. Pregabalin in central neuropathic pain associated with spinal cord injury: a placebo-controlled trial. Neurology. 2006; 67(10):1792-800. 
20. Vranken JH, Dijkgraaf MG, Kruis MR, van der Vegt MH, Hollmann MW, Heesen M. Pregabalin in patients with central neuropathic pain: a randomized, double-blind, placebo-controlled trial of a flexible-dose regimen. Pain. 2008;136(1-2):150-7.

21. Kim JS, Bashford G, Murphy TK, Martin A, Dror V, Cheung R. Safety and efficacy of pregabalin in patients with central post-stroke pain. Pain. 2011;152(5):1018-23.

22. Levendoglu F, Ogun CO, Ozerbil O, Ogun TC, Ugurlu H. Gabapentin is a first line drug for the treatment of neuropathic pain in spinal cord injury. Spine. 2004;29(7):743-51.

23. Rintala DH, Holmes SA, Courtade D, Fiess RN, Tastard LV, Loubser PG. Comparison of the effectiveness of amitriptyline and gabapentin on chronic neuropathic pain in persons with spinal cord injury. Arch Phys Med Rehabil. 2007;88(12):1547-60.

24. Leijon G, Boivie J. Central post-stroke pain - a controlled trial of amitriptyline and carbamazepine. Pain. 1989;36(1):27-36.

25. Vestergaard K, Andersen G, Gottrup H, Kristensen BT, Jensen TS. Lamotrigine for central poststroke pain: a randomized controlled trial. Neurology. 2001;56(2):184-90.

26. Finnerup NB, Sindrup SH, Bach FW, Johannesen IL, Jensen TS. Lamotrigine in spinal cord injury pain: a randomized controlled trial. Pain. 2002;96(3):375-83.

27. Vollmer TL, Robinson MJ, Risser RC, Malcolm SK. A randomized, double-blind, placebo-controlled trial of duloxetine for the treatment of pain in patients with multiple sclerosis. Pain Pract. 2014;14(8):732-44.

28. Rog DJ, Nurmikko TJ, Friede T, Young CA. Randomized, controlled trial of cannabis-based medicine in central pain in multiple sclerosis. Neurology. 2005;65(6):812-9.

29. Chaparro LE, Wiffen PJ, Moore RA, Gilron I. Combination pharmacotherapy for the treatment of neuropathic pain in adults. Cochrane Database Syst Rev, 2012; (7):CD008943.

30. Gilron I, Jensen TS, Dickenson AH. Combination pharmacotherapy for management of chronic pain: from bench to bedside. Lancet Neurol. 2013;12(11):1084-95.

31. Finnerup NB, Sindrup SH, Jensen TS. The evidence for pharmacological treatment of neuropathic pain. Pain. 2010;150(3):573-81.

32. Lynch ME, Campbell F. Cannabinoids for treatment of chronic non-cancer pain; a systematic review of randomized trials. $\mathrm{Br} \mathrm{J}$ Clin Pharmacol. 2011;72(5):735-44.

33. Dworkin RH, Backonja M, Rowbotham MC, et al. Advances in neuropathic pain: diagnosis, mechanisms, and treatment recommendations. Arch Neurol. 2003;60(11):1524-34.

34. Edlund MJ, Martin BC, Russo JE, DeVries A, Braden JB, Sullivan MD. The role of opioid prescription in incident opioid abuse and dependence among individuals with chronic noncancer pain: the role of opioid prescription. Clin J Pain. 2014;30(7):557-64.

35. Fischer B, Jones W, Urbanoski K, Skinner R, Rehm J. Correlations between prescription opioid analgesic dispensing levels and related mortality and morbidity in Ontario, Canada, 2005-2011. Drug Alcohol Rev. 2014;33(1):19-26.
36. Imtiaz S, Shield KD, Fischer B, Rehm J. Harms of prescription opioid use in the United States. Subst Abuse Treat Prev Policy. 2014;9:43.

37. Hucho T, Levine JD. Signaling pathways in sensitization: toward a nociceptor cell biology. Neuron. 2007;55(3):365-76.

38. Campbell JN, Meyer RA. Mechanisms of neuropathic pain. Neuron. 2006;52(1):77-92.

39. Andersen G, Vestergaard K, Ingeman-Nielsen M, Jensen TS. Incidence of central post-stroke pain. Pain. 1995;61(2): 187-93.

40. Zeilig G, Enosh S, Rubin-Asher D, Lehr B, Defrin R. The nature and course of sensory changes following spinal cord injury: predictive properties and implications on the mechanism of central pain. Brain J Neurol. 2012;135(Pt 2):418-30.

41. Bennett GJ. What is spontaneous pain and who has it? J Pain J Am Pain Soc. 2012;13(10):921-9.

42. Krames E. Spinal cord stimulation: indications, mechanism of action, and efficacy. Curr Rev Pain. 1999;3(6):419-26.

43. Dworkin RH, O'Connor AB, Kent J, et al. Interventional management of neuropathic pain: NeuPSIG recommendations. Pain. 2013;154(11):2249-61.

44. Aly MM, Saitoh Y, Hosomi K, Oshino S, Kishima H, Yoshimine T. Spinal cord stimulation for central poststroke pain. Neurosurgery. 2010;67(3 Suppl Operative):ons206-12; discussion ons12.

45. Hosobuchi Y, Adams JE, Rutkin B. Chronic thalamic stimulation for the control of facial anesthesia dolorosa. Arch Neurol. 1973; 29(3):158-61.

46. Mazars G, Merienne L, Cioloca C. [Treatment of certain types of pain with implantable thalamic stimulators]. Neuro-Chirurgie. 1974;20(2):117-24.

47. Boccard SG, Pereira EA, Moir L, Aziz TZ, Green AL. Long-term outcomes of deep brain stimulation for neuropathic pain. Neurosurgery. 2013;72(2):221-30; discussion 31.

48. Tsubokawa T, Katayama Y, Yamamoto T, Hirayama T, Koyama S. Chronic motor cortex stimulation for the treatment of central pain. Acta Neurochir Suppl. 1991;52:137-9.

49. Henderson JM, Lad SP, Chao K. Motor Cortex Stimulation. In: Winn HR, editor. Youmans neurological surgery. 6th edition, New York: Elsevier Health Sciences; 2011. pp. 1831-4.

50. Henderson JM, Boongird A, Rosenow JM, LaPresto E, Rezai AR. Recovery of pain control by intensive reprogramming after loss of benefit from motor cortex stimulation for neuropathic pain. Stereotact Funct Neurosurg. 2004;82(5-6):207-13.

51. Sachs AJ, Babu H, Su YF, Miller KJ, Henderson JM. Lack of efficacy of motor cortex stimulation for the treatment of neuropathic pain in 14 patients. Neuromodulation. 2014;17(4):303-10; discussion 10-11.

52. Deer TR, Pope JE, Hayek S, et al. The Polyanalgesic Consensus Conference (PACC): recommendations on intrathecal drug infusion systems best practices and guidelines. Neuromodulation. 2017; 20(2):96-132. 